\title{
A DISTINÇÃO ENTRE AS ESTRUTURAS DE PODER EM JACQUES RANCIÈRE E
} MICHEL FOUCAULT

\section{LA DISTINCTION ENTRE LES STRUCTURES DE POUVOIR CHEZ JACQUES RANCIÈRE ET MICHEL FOUCAULT}

Michelly Alves Teixeira ${ }^{1}$

(michellyteixeira@hotmail.com)

\section{RESUMO}

Neste trabalho, apresentaremos o prelúdio de um debate que tem grandes implicações quando pensamos as definições de poder defendidas tanto por Michel Foucault quanto por Jacques Rancière. Apesar de ambos os autores formularem diagnósticos no tocante à política social francesa, nosso problema é entender as estruturas de poder, as manifestações da ordem política e policial, bem como o movimento de contraposição que estrutura a discussão, visto que, apesar da proximidade de Rancière para com as teses foucaultianas, existe também um desvio, capaz de formular a reconfiguração dos espaços de maneira distinta, com base em disposições de poder como política e polícia.

Palavras-chave: Poder. Política. Polícia. Biopoder.

\section{RÉSUMÉ}

Dans ce travail, nous présenterons le prélude d'un débat qui a des implications encore plus importantes quand on pense aux définitions du pouvoir défendues tant par Michel Foucault que par Jacques Rancière. Bien que les deux auteurs formulent des diagnostics en ce qui concernet la politique sociale française, notre problème est de comprendre les structures de pouvoir, les manifestations de l'ordre politique et policier ainsi que le mouvement d'opposition qui structure la discussion. Malgré la proximité de Rancière avec les thèses foucaldiennes, il y a aussi un détournement, capable de formuler la reconfiguration des espaces d'une manière distincte, sur la base de dispositions de pouvoir comme politique et police.

Mots-clés: Pouvoir. Politique. Police. Biopouvoir.

\section{INTRODUÇÃO}

\footnotetext{
${ }^{1}$ Mestranda em Filosofia pela Universidade de Brasília (UnB). CV Lattes: http://lattes.cnpq.br/6860370367827142. ORCID: https://orcid.org/0000-0002-0842-8824.
} 
O poder, enquanto domínio, soberania, significa em seu sentido geral a disposição de força e autoridade, em oposição à sujeição e obediência, em se tratando da comunidade política. Rancière, em seu livro $O$ desentendimento, cujo teor é nosso objeto de estudos, pensa uma fragmentação das forças sociais que formam a partilha do sensível ${ }^{2}$, ou a comunidade. Só ao se problematizar o que é a política é que ela surge não apenas como a prática de governar ou a administração do Estado e de nações, mas como espaço de embate, cuja ordem é exibir uma espécie de savoir-faire, pela igualdade de voz, ao se lutar contra qualquer tipo de exceção provocada pela ordem policial no espaço público. Em oposição a isso, temos a polícia, que pensa o espaço político como equilíbrio de interesses, que tende a liquidar a verdadeira finalidade da prática política ao ocasionar ações que rompem com a prática do conflito, ao reforçar formas já preestabelecidas de controle repressivo cuja finalidade única é reprimir a voz e a participação dos "sem-voz" no processo democrático.

Diferentemente de Rancière, Foucault (2008, p. 138) analisa a estrutura do controle social a partir de relações que, segundo afirma, não se operam simplesmente pela consciência ou pela ideologia, mas começam com o corpo, isto é, pelo sujeito. Consequentemente, o conceito de biopoder toma forma enquanto prática de poder que captura a vida humana como centro de suas estratégias ao trazer à tona as técnicas de controle, a submissão dos corpos e a disciplina. Assim, pensar Foucault é abordar as formas de poder e conhecimento a partir do controle social e das instituições que compõem a sociedade. Nosso objeto de estudos será analisado através dos textos de Foucault Segurança, território, população e os contidos na coletânea organizada por Roberto Machado, Microfísica do poder, tendo por meta a análise dos mecanismos de regulação que movem o controle das populações e são responsáveis por potencializar o conceito de biopoder, cuja finalidade é fazer da vida instrumento de poder. Toda essa base teórica nos será alicerce para pensar a problemática que propomos: existe alguma distinção entre as formas de poder estruturadas por Rancière e o pensamento foucaultiano? Para isso, apresentaremos as definições de poder defendidas tanto por Foucault quanto por Rancière, visto que, apesar de tais autores pensarem as formas de repressão no interior da ordem sensível, há uma espécie de distinção entre poder, política e organização dos espaços que institui o debate.

\footnotetext{
${ }^{2}$ Para o autor, partilha significa duas coisas: a participação em um conjunto comum e, inversamente, a separação, a distribuição em quinhões. Uma partilha do sensível é, portanto, o modo como se determina no sensível a relação entre um conjunto comum partilhado e a divisão de partes exclusivas. (RANCIÈRE, 1995, p. 7).
} 
Mesmo que o percurso proposto pelos autores seja pensar os aparatos que modificam, prendem e configuram a organização social, veremos que ambos organizam o pensamento de maneiras distintas. Nesse sentido, em um primeiro momento, apresentaremos como Rancière define a organização de poderes no sensível tendo por base sua noção de configuração dos espaços posta pela política e polícia; em seguida, apresentaremos as teses que compõem parte do todo foucaultiano, a fim de repensarmos as considerações metodológicas sobre o poder e para, em um terceiro momento, analisarmos a crítica feita por Jacques Rancière às definições de biopoder e biopolítica presentes na obra de Foucault.

\section{O CONFLITO ENTRE POLÍTICA E POLÍCIA EM RANCIÈRE}

A perspectiva de Rancière acerca das noções de poder $^{3}$ e política carrega como pressuposto a inserção em um debate polêmico, visto que o conceito de política, diferentemente do que sugere parte da tradição filosófica contemporânea, não se insere no princípio da política como obtenção e manutenção do poder. Mesmo quando pensa a filosofia política contemporânea, o autor manifesta - em busca de propor novas formas de discussão sobre o conceito de política - que ela está se afastando de sua natureza ${ }^{4}$ ao se ocupar com formas de administração do Estado e do poder. É nesse sentido que Rancière nos diz que a filosofia se torna "política" quando "acolhe a aporia ou o embaraço próprio da política" (RANCIÉRE, 2018, p. 9). Diante da urgência de se pensar a filosofia política, Rancière busca identificar os limites conceituais contemporâneos, e é por isso que conceitos importantes na obra de Jacques Rancière, como política e polícia, são a base para delimitarmos o problema aqui proposto.

Diante desse cenário, Rancière faz a distinção entre duas formas de poder presentes no sensível $^{5}$ : política e polícia, ou seja, a prática política e a prática policial, as quais o autor define

\footnotetext{
${ }^{3}$ Aqui, a política, vista como "poder do povo", distingue-se do poder como forma estatal ou mesmo privatização do poder, conforme manifestado pelo autor em textos subsequentes. Nesse sentido, Rancière afirma que o poder democrático está em risco, dada a captura do poder estatal por uma minoria de oligarcas; "isso quer dizer que o poder do povo deve ter seus organismos e suas formas de ação autônomas em relação às formas estatais. De outro lado, isso quer dizer que aquilo chamamos de democracia representativa é um modelo misto, submetido a duas formas contraditórias" (RODRIGUES, C. O poder do povo. Entrevista com Jacques Rancière. Acervo combate racismo ambiental, 2014. Disponível em: <https://acervo.racismoambiental.net.br/2014/09/17/o-poderdo-povo-entrevista-com-jacques-ranciere/>. Acesso em 9 de setembro de 2019).

${ }^{4}$ Pellejero $(2013$, p. 37) identifica que a fundação da filosofia política na obra de Rancière remete a modos de vida e formas de existência, como quando em Aristóteles é estabelecida a distinção entre os seres dotados de voz e os seres dotados de linguagem.

${ }^{5}$ Para o autor, a partilha do sensível, ou o sensível, delineia a estrutura da comunidade política, tendose por ponto de chegada que é mediante o encontro da estética com a política que organizamos o
} 
não como dois modos de vida, "mas duas partilhas do sensível, duas maneiras de dividir um espaço sensível, [...] de ouvir ou de não ouvir os sujeitos que os designam ou argumentam em seu favor" (MOSTAÇO, 2010, p. 76). Ou seja, o sensível, ou o âmbito do social, divide-se pela disposição de poderes organizada pela polícia em oposição à política - e esta é sempre um modo de manifestação que tende a se pronunciar contra essa disposição de poderes preestabelecida pela polícia. Desse modo, podemos afirmar tratar-se de um paradoxo presente na comunidade, capaz de promover conflitos tanto entre os benfeitores policiais que submetem o povo a silenciamentos e à submissão quanto aos destituídos de poderes, definidos por Rancière como sem-voz ou silenciados, que só em potência apresentam-se como sujeitos políticos.

Nesse caso, a polícia nos é dada como um “conjunto de processos pelos quais se operam [...] a organização dos poderes, a distribuição dos lugares e funções e os sistemas de legitimação dessa distribuição" (RANCIÉRE, 1996, p. 41). Ou seja, na proposta do autor, o conceito de polícia perde a significação tradicional que costumamos ilustrar com atos agressivos e agentes da ordem pública, comumente nomeada de "baixa-política". Nesse sentido, precisamos desconstruir a ideia de que a polícia é apenas instrumento de poder ou parte constitutiva do Estado, já que para Rancière sua manifestação tem um sentido amplo e, portanto, ela é capaz de estruturar o espaço em lugares, funções e aptidões:

A polícia é, na sua essência, a lei [...] que define as partilhas entre os modos do fazer, os modos de ser e os modos do dizer, que faz que tais corpos sejam designados por seu nome para tal lugar e tal tarefa; é uma ordem do visível e do dizível que faz com que essa atividade seja visível e outra não o seja, que essa palavra seja entendida como discurso e outra como ruído. (RANCIÈRE, 2018, p. 43)

Nesse sentido, vimos que a polícia não é definida como instituição de poder, mas como "um princípio de partilha do sensível no interior da qual podem ser definidas as estratégias e as técnicas de poder" (MOSTAÇO, 2010, p. 78). Assim, um corpo objeto de poder é um corpo que se situa na partilha policial, e, consequentemente, é introduzido nas práticas e nos efeitos do poder, vítima de intervenções em sua individualização e nas práticas cotidianas de socialização. Quando Rancière faz a crítica à instância do biopoder na análise foucaultiana, está partindo do pressuposto de que tanto a política quanto a polícia estão

[...] no domínio duma análise restrita do exercício do poder, uma análise que se limitaria a considerar a partilha policial dos corpos

sensível; é nesse encontro que nos damos a entender, vemos e construímos a visibilidade e inteligibilidade dos acontecimentos políticos. 
e das agregações dos corpos, uma análise que diria apenas respeito aos efeitos do poder na individualização da vida e na socialização das populações. (PELLEJERO, 2013, p. 40)

Já o conceito de política, em oposição ao conceito anterior, implica formas de poder coletivo que resultam na ruptura de organizações do poder oligárquico e do funcionamento de instituições. Essa ruptura pode reorganizar o espaço onde as partes, as parcelas e as ausências de parcela se estabeleciam (RANCIÉRE, 1996, p. 42). Desse modo:

\begin{abstract}
A polícia é a partilha do sensível que relaciona a construção do comum de uma comunidade com a construção das propriedades - as semelhanças e diferenças - caracterizando os corpos e os modos de sua agregação. Ela estrutura o espaço perceptível em termos de lugares, funções, aptidões etc., excluindo todo suplemento. A política não é, - nada mais - do que o conjunto de atos que constroem uma "propriedade" suplementar, uma propriedade biológica e antropologicamente desaparecida, do que a igualdade dos seres falantes. (MOSTAÇO, 2010, p. 76)
\end{abstract}

Para Rancière, a atividade política, diferentemente da atividade policial, faz ver o que antes estava restrito ao silêncio, faz ser possível manifestar um discurso ou mesmo uma demanda, e pode ser exemplificada por "manifestantes de ruas ou barricadas que literalizam o ‘espaço público' e as vias de comunicação urbanas” (RANCIÉRE, 1996, p. 42). Assim, para o autor, falemos de um "poder real da coletividade sobre suas condições de existência e de uma real igualdade dos indivíduos" (RANCIÉRE, 2014, Kindle Edition), já não fixados somente na representação estatal, mas através de um modo de manifestação cuja capacidade de desfazer as divisões do sensível da ordem policial configura a ordem preestabelecida e delineia um mundo comum diferente. No entanto, a lógica política está amarrada à lógica policial, visto que a política não tem objetos ou questões próprias, mas somente se manifesta quando o estado policial sobressai diante das demandas populares. É nesse sentido que ambas as relações são mediadas por uma série de conceitos, entre eles o conceito de poder, uma vez que, a fim de que uma coisa seja política, o encontro entre a lógica policial e a lógica igualitária torna-se fator determinante.

Para o poder da política se manifestar, o poder policial precisa estar preestabelecido no ordenamento sensível; "nenhuma coisa é então por si política. Mas qualquer coisa pode vir a sê-lo se der ocasião ao encontro das duas lógicas" (RANCIÉRE, 1996, p. 45). Nesse caso, eleições, manifestações e greves podem ser política; há política graças ao poder paradoxal de pessoas que não são nada, não têm qualidades especiais e não possuem títulos senão ao se desvencilharem do monopólio de uma oligarquia governamental. 
Assim, para Rancière, movimentos como Primavera Árabe, Indignados, Occupy etc. são políticos por impulsionarem um modo de manifestação capaz de desfazer as divisões do sensível que circunscrevem os indivíduos ao âmbito privado e os reduz à lógica do mercado e do controle estatal.

Portanto, para pensarmos essas organizações do sensível precisamos esclarecer que a política existe como um modo de reafirmação do poder do povo contra as formas de repressão do poder oligárquico. Ela se vale do princípio de igualdade, princípio buscado pelos seres falantes (FREIRE, 1995), uma vez que "o poder do povo [...] é simplesmente o poder próprio daqueles que não têm nem título para governar nem para serem governados" (RANCIÉRE, 2014, Kindle Edition). Essa legitimidade para fazer parte do governo surge com a emancipação intelectual quando há a instrução do povo, assunto que Rancière desenvolve com mais profundidade em outras publicações.

\section{A MECÂNICA DO PODER EM FOUCAULT}

Foucault, ao voltar-se à noção de poder nas primeiras fases de seu curso principalmente em 1970 -, pensa em um primeiro momento o poder de normalização fundado com base em procedimentos jurídicos de castigo; em um segundo momento, entre os anos de 1975 e 1976, o ciclo se fecha com os mecanismos que pretendem "defender a sociedade" (FOUCAULT, 1997, p. 67). Detenhamo-nos na segunda fase, quando Foucault prepara uma análise concreta das relações de poder, cujo princípio não é centralizado no poder somente como modelo jurídico, mas sobretudo como técnicas de coerção capazes de fabricar sujeitos.

A mecânica do poder em Foucault começa com a preocupação com sua forma e exercício, suas especificidades e táticas, e sendo mediação para se pensar uma análise das instituições, visto que as engrenagens do poder, que são base para o desenvolvimento da instituição, não se restringem somente ao campo econômico. Essa mecânica do poder na qual Foucault sustenta sua tese começa a ser investigada com mais profundidade em 1968, quando as lutas cotidianas se veem intrincadas nas malhas finas do poder (FOUCAULT, 1979, p. 6). Nesse sentido, pensar a concretude do poder por meio das demandas sociais constitui o poder sob duas lógicas: a primeira, soberana, capaz de delimitar os direitos dos indivíduos, capturados pela articulação entre lei e repressão característica da instância da regra, do interdito e da lógica da censura; a segunda, instituída pelo poder normativo (biopoder), capaz de influenciar de modo furtivo os sujeitos através de mecanismos do poder que 
controla e normatiza a conduta dos corpos singulares (disciplinar), ou por meio do indivíduo enquanto população (regulação).

Sobre uma instância de poder, Foucault exemplifica: “[...] o internamento psiquiátrico, a normalização mental dos indivíduos, as instituições penais têm sem dúvida uma importância muito limitada se se procura somente sua significação econômica" (FOUCAULT, 1979, p. 6). Isso exige pensar tal instância como parte constituinte de um sistema que se firma mediante técnicas e táticas de controle. Por isso, diante do grande desenvolvimento teórico que Foucault estabelece para definir a noção de poder (poder soberano e biopoder), resolvemos abarcar somente parte da tese, cujo propósito vai de encontro à leitura rancièriana e se esgota quando o poder é tido como controle sobre os indivíduos e sobre os corpos. Em vista disso, nossa linha de pensamento detém-se na instância do biopoder, que se desenvolve na sociedade por meio dos mecanismos de regulação do Estado, controle populacional e processos biológicos, sempre visando ao surgimento de novas tecnologias que se caracterizam por fazer do homem instrumento de controle, suscetível ao tratamento estatístico e aos métodos de regulação.

Nos Resumos dos cursos do Collége de France, sua análise das relações de poder, a princípio, visa a abandonar o modelo jurídico da soberania, que tem por fim dar conta da gênese ideal do Estado, para pensar aquelas relações como relações de força (FOUCAULT, 1997, p. 71). É com a instauração da economia do poder, forma de poder centralizado no Estado, que começa a surgir a necessidade de fazer nascerem instituições militares; essa transformação se concretiza quando o discurso da guerra se implementa socialmente e, com isso, torna-se "fundo permanente de todas as instituições de poder" (FOUCAULT, 1997, p. 73), constituindo-se como realização das instituições, leis e ordenamento, ou seja, como manifestação da paz.

Sob essa perspectiva, a passagem do poder detido a um "Estado de população" nos faz pensar novas mecânicas que compõem essas manifestações de poder, capazes de assegurar sua regulação ao disporem de novas técnicas e de novos problemas, como assegurar o binário população-riqueza criando mecanismos de fiscalização - o que, em Segurança, território e população, enquanto demanda de desenvolvimento capitalista, segue criando formas de relações sociais e econômicas ao direcionar as formas de organização política. Nesse sentido, as exigências de uma formação de "governamentalidade" política, conceito que não desenvolvemos com tanta profundidade, criam "uma arte de governar cuja racionalidade tem seus princípios e seu domínio de aplicação específico no Estado” (FOUCAULT, 1997, p. 83). Nesse momento, surgem formas de controle social constitutivas da especificidade do biopoder concentradas em "dois grandes conjuntos de saber e de tecnologia políticos: uma tecnologia diplomático-militar que consiste em assegurar e 
desenvolver as forças do Estado por um sistema de alianças e pela organização de um aparelho armado" (FOUCAULT, 1997, p. 83) e outra, que constitui a polícia, em que os objetivos baseiam-se no ordenamento a fim de se garantirem a segurança e a qualidade de vida dos indivíduos, ou seja, o

Desenvolvimento do Estado de concorrência (econômico-militar), desenvolvimento do Estado de Welfare (riqueza-tranquilidade-felicidade), são esses dois princípios que a "polícia", entendida como arte racional de governar, deve poder coordenar. Ela é concebida nessa época como um tipo de "tecnologia das forças estatais". (FOUCAULT, 1997, p. 85)

Eis aí o que constitui o objeto da nova razão governamental, ou governamentalidade.

Com o poder econômico e suas formas de manifestação, temos o valor mercantilista dos corpos, que é peça e porção fundamental na elaboração das forças do Estado. O gerenciamento dessa nova forma de lucro proporciona a criação de novas formas institucionais de poder, tanto em âmbito público quanto privado, capazes de resultar em novas maneiras de governar, porque o poder não mais se firma sobre a individualidade do soberano, mas sobretudo por meio da multiplicidade de formas de governar:

O desenvolvimento [...] deve ser reinscrito nos quadros gerais de uma "biopolítica", que tende a tratar a "população" como um conjunto de seres vivos e coexistentes, que apresentem traços biológicos e patológicos particulares, e que, por conseguinte, dizem respeito a técnicas e saberes específicos. (FOUCAULT, 1997, p. 86)

A partir desse pressuposto, acrescente-se que, "por milênios, o homem permaneceu o que era para Aristóteles: um animal vivente e, além disso, capaz de existência política; o homem moderno é um animal em cuja política está em questão a sua vida de ser vivente" (FOUCAULT, 1976, p. 127 apud AGAMBEN, 2002, p. 11). Foucault, quando faz a análise do poder, examina minuciosamente as relações de força e as estratégias, visto que o poder tem por finalidade vir de todos os lados, exercido com base em superestruturas. Com o poder soberano, conclui-se que os problemas, outrora voltados somente para a vida e para a população em sociedade, atualmente seguem capturados para o interior de tecnologias de governo.

Nesse sentido, podemos dizer que o biopoder se subdivide em anátomo-política, a disciplinarização dos corpos singulares agindo estritamente sobre os indivíduos, e biopolítica, aplicada como regularização dos processos de uma população mediante formas de normalização. Isso reforça a tese presente em Microfísica do poder de que a 
biopolítica é a captura do corpo e da vida em sociedade pelas instituições de poder, reforçandose a questão proposta de como o controle da sociedade sobre os indivíduos não se opera simplesmente pela consciência ou pela ideologia, mas começa com o corpo. Assim, sua principal manifestação é o poder, que, intrínseco a essa nova forma de sociedade que toma a vida como centro de estratégias ao implantar técnicas de controle, é capaz de submeter os corpos a formas disciplinares.

Logo, se o triunfo do capitalismo se constitui graças ao controle disciplinar praticado pelo biopoder - o qual produz, mediante uma série de tecnologias, os "corpos dóceis" de que necessita -, seu princípio deve-se ao auge da governamentalidade, que é fundamental para pensarmos o apogeu das instituições, os procedimentos de análises e reflexões, cálculos e táticas que exercem o poder, e o que faz com que as técnicas de governo tornem-se parte de uma sociedade controlada por dispositivos.

Em vista disso, Rancière faz a separação entre a polícia e as formas de manifestação populares, definidas como política. Ambas as formas de poder, política e polícia, fazem parte da comunidade política. O ponto-chave de Rancière é fazer com que uma forma de poder dependa da outra - ou seja, para que a polícia não sobressaia como forma de representação governamental que exclui o povo de seu caráter decisório, torna-se imprescindível que a política, como forma de manifestação popular, ou democrática, ocupe espaços e se oponha a qualquer forma de manifestação capaz de minimizar o poder popular pela lógica da representação. De início, podemos afirmar que a crítica proposta por Foucault acerca da noção de poder em muito pouco se distingue da crítica feita por Rancière das formas de organização policial, cujo sentido é também a institucionalização do poder. Entretanto, diferentemente de Rancière, Foucault não pensa o poder como forma política, mas somente como organização policial dos espaços.

\section{FORMAS DE PODER EM FOUCAULT E RANCIÈRE}

Vimos que para Rancière as formas de poder, política e polícia, são instâncias que, mesmo paradoxais, não são excludentes, uma vez que a política depende da prática policial de intervenção dos corpos para ocupar lugar no sensível e fazer com que o espaço de fala pertença também a essa parcela dos sem-parcela. Mesmo que Rancière defina um novo conceito de polícia, sua tese está distante da tese foucaultiana de disciplinarização dos espaços - aparato estatal cuja finalidade é o controle dos corpos - , porque o 
sentido de polícia apontado por Rancière é uma estrutura de governo que, dependente das relações sociais, manifesta uma espécie de rigidez nas funções do Estado, através de leis que estruturam um conjunto de processos que se operam na organização dos poderes, na distribuição dos lugares de fala e nas funções que se legitimam.

Em vista disso, a crítica de Rancière ao conceito de biopoder defendido por Foucault tem por princípio pensar a polícia; entretanto, não a constitui também como forma política, já que a política não é parte de todas as formas de relação, mas se manifesta através de um movimento paradoxal no interior do processo democrático, em que há uma urgência de participação do povo (sem voz) no ordenamento do sensível. Um exemplo que o próprio Rancière coloca é a estrutura do lar, que, sendo também um espaço político, não se firma somente em ordenações de poderes, mas com base em conflitos - como quando existe uma relação de dominação entre um casal e, nesse momento, o dominado supera a situação de dominação com alguma espécie de manifestação. Portanto, a política tem a capacidade de contestar o ordenamento estabelecido quando aqueles excluídos ou fadados ao anonimato resolvem revelar-se iguais aos soberanos e a todas as estruturas de poder.

Se em Rancière os corpos ou os sem nome, como aponta o autor, podem ir além do processo de dominação quando decidem se colocar em estado de igualdade com a oligarquia, em Foucault o ordenamento do sensível é gerido valendo-se de mecanismos que produzem corpos dóceis, submetidos a um sistema de controle. Nesse processo, temos a polícia (no sentido rancièriano) sobrepondo a ordem política, e para Rancière a ideia de sujeito político e de política como modo de vida (MOSTAÇO, 2010, p. 76) não pode ser caracterizada do modo como Foucault a investiga, sendo o corpo apenas objeto de poder, uma vez que

\footnotetext{
O animal político aristotélico é um animal dotado de politicidade, quer dizer, capaz de agir como sujeito participante do agir político, o que, nos termos aristotélicos, significa um ser participante do poder da arkhé, ou seja, como sujeito e como objeto. O corpo referido pela "biopolítica" de Foucault é um corpo objeto de poder, um corpo situado na partilha policial dos corpos e agregações dos corpos. A biopolítica foi introduzida por Foucault como diferença específica nas práticas do poder e nos efeitos de poder, na maneira como o poder opera nos efeitos de individualização dos corpos e na socialização das populações. Ora, essa questão não é aquela da política. A questão da política começa onde o que está em questão é o status do sujeito apto de se ocupar com a comunidade. (MOSTAÇO, 2010, p. 76)
}

Ou seja, os status de sujeitos foucaultianos estão inteiramente voltados para a partilha policial rancièriana, enquanto os sujeitos políticos de Rancière, já possuidores da capacidade de romper com o ordenamento sensível, conseguem 
ocupar a comunidade. Somente quando a manifestação de igualdade rompe com a ordem de submissão o sistema revela que há uma urgência de reconhecimento do povo e de ocupação na ordem do sensível. Nesse processo, temos a política sobrepondo a ordem policial.

\section{CONSIDERAÇÕES FINAIS}

Foucault encarrega-se apenas do plano do poder; no entanto, para Rancière a polícia não se define como uma instituição de poder, "mas um princípio de partilha do sensível no interior da qual podem ser definidas as estratégias e as técnicas do poder” (MOSTAÇO, 2010, p. 78). Em se tratando da tese de Rancière, o que é analisado por Foucault fica apenas no plano policial, visto que, se "Foucault pode falar, indiferentemente, em biopoder e em biopolítica, é porque seu pensamento sobre política foi construído em torno da questão do poder, uma vez que jamais esteve teoricamente interessado na questão da subjetivação política" (MOSTAÇO, 2010, p. 77). Ao tratar da distinção dos dois termos, política e polícia, Rancière caminha por diferentes direções, distantes da análise foucaultiana. 


\section{REFERÊNCIAS BIBLIOGRÁFICAS}

AGAMBEN, G. Homo sacer: o poder soberano e a vida nua. Belo Horizonte: Editora UFMG, 2002.

FREIRE, V. T. Os riscos da razão: a luta de classes não é moderna; foi pensada pelos antigos. Folha de S. Paulo, 1995. Disponível em:

<https://www1.folha.uol.com.br/fsp/1995/9/10/mais!/4.html>. Acesso em 2 de abril de 2019.

FOUCAULT, M. Microfísica do poder. Rio de Janeiro: Edições Graal, 1979.

. Resumos dos cursos do Collége de France (1970-1982). Rio de Janeiro: Jorge

Zahar Editor, 1997.

. Segurança, território e população. São Paulo: Martins Fontes, 2008.

MOSTAÇO, E. Urdimento - Revista de Estudos em Artes Cênicas/Universidade do Estado de Santa Catarina. Programa de Pós-Graduação em Teatro apud Entrevista à revista Multidões, por Eric Alliez. Florianópolis: UDESC/CEART, v. 1, n. 15, out. 2010.

PELLEJERO, E. Aquém da biopolítica: a parte (sem parte) de Jacques Rancière. Rev. Filos., Aurora, Curitiba, v. 25, n. 37, p. 35-55, jul./dez. 2013.

RANCIÈRE, J. Ainda se pode falar de democracia?. Lisboa: KKYM, 2014. In: <https://www.amazon.com.br/Ainda-falar-democracia-ensaios-brevesebook/dp/B00J3ZF2OM >.

RANCIÈRE, J. A partilha do sensível: estética e política. São Paulo: Editora 34, 2009. . O desentendimento: política e filosofia. São Paulo: Editora 34, 1996. . O desentendimento: política e filosofia. São Paulo: Editora 34, 2018. . O ódio à democracia. São Paulo: Boitempo, 2014. . Políticas da escrita. São Paulo: Editora 34, 1995.

RODRIGUES, C. O poder do povo. Entrevista com Jacques Rancière. Acervo combate racismo ambiental, 2014. Disponível em: <https://acervo.racismoambiental.net.br/2014/09/17/o-poder-do-povo-entrevista-com-jacques-

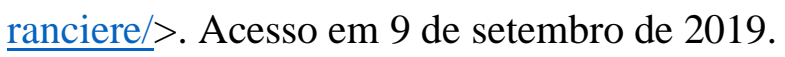

